\title{
CD40/anti-CD40 antibody complexes which illustrate agonist and antagonist structural switches
}

\author{
Maria A. Argiriadi ${ }^{*}$, Lorenzo Benatuil², levgeniia Dubrovska ${ }^{3}$, David A. Egan³ ${ }^{3}$ Lei Gao², Amy Greischar ${ }^{3}$, \\ Jennifer Hardman², John Harlan³, Ramesh B. Iyer ${ }^{3}$, Russell A. Judge ${ }^{3}$, Marc Lake ${ }^{3}$, Denise C. Perron², \\ Ramkrishna Sadhukhan², Bernhard Sielaff', Silvino Sousa ${ }^{2}$, Rui Wang ${ }^{2}$ and Bradford L. McRae ${ }^{2}$
}

\begin{abstract}
Background: CD40 is a $48 \mathrm{kDa}$ type I transmembrane protein that is constitutively expressed on hematopoietic cells such as dendritic cells, macrophages, and B cells. Engagement of CD40 by CD40L expressed on T cells results in the production of proinflammatory cytokines, induces T helper cell function, and promotes macrophage activation. The involvement of CD40 in chronic immune activation has resulted in CD40 being proposed as a therapeutic target for a range of chronic inflammatory diseases. CD40 antagonists are currently being explored for the treatment of autoimmune diseases and several anti-CD40 agonist mAbs have entered clinical development for oncological indications.

Results: To better understand the mode of action of anti-CD40 mAbs, we have determined the $x$-ray crystal structures of the ABBV-323 (anti-CD40 antagonist, ravagalimab) Fab alone, ABBV-323 Fab complexed to human CD40 and FAB516 (anti-CD40 agonist) complexed to human CD40. These three crystals structures 1) identify the conformational CD40 epitope for ABBV-323 recognition 2) illustrate conformational changes which occur in the CDRs of ABBV-323 Fab upon CD40 binding and 3) develop a structural hypothesis for an agonist/antagonist switch in the LCDR1 of this proprietary class of CD40 antibodies.

Conclusions: The structure of ABBV-323 Fab demonstrates a unique method for antagonism by stabilizing the proposed functional antiparallel dimer for CD40 receptor via novel contacts to LCDR1, namely residue position R32 which is further supported by a closely related agonist antibody FAB516 which shows only monomeric recognition and no contacts with LCDR1 due to a mutation to L32 on LCDR1. These data provide a structural basis for the full antagonist activity of ABBV-323.
\end{abstract}

Keywords: CD40, Crystal structure, Agonist, Antagonist, Antibody

\section{Background}

$\mathrm{CD} 40$ is a $48 \mathrm{kDa}$ type I transmembrane protein that is expressed on a wide range of hematopoietic (B cells, monocytes/macrophages, dendritic cells) and nonhematopoietic (activated epithelium, endothelium) cells. Its ligand, CD154 or CD40L, has a more restricted expression pattern and is found primarily on activated $\mathrm{T}$ cells, B cells, and platelets. Engagement of CD40 by CD40L results in the recruitment of TNF receptor

\footnotetext{
* Correspondence: maria.argiriadi@abbvie.com

${ }^{1}$ AbbVie Bioresearch Center, 381 Plantation Street, Worcester, MA 01605, USA Full list of author information is available at the end of the article
}

associated factors (TRAFs) to the cytoplasmic domain of CD40 [1]. Phosphorylation of various TRAF proteins results in activation of both canonical and non-canonical NF-kB pathways. TRAF6-dependent PI3K activation is a critical survival signal while TRAF2/TRAF6 have redundant functions in NF-kB activation and upregulation of CD80 and ICAM-1 expression [2]. Much of our understanding of CD40/CD40L biology comes from the interaction between antigen presenting cells [CD40 expression on either dendritic cells (DC) or B cells] and CD40L-expressing T cells. Cell-cell interactions between antigen presenting cells and $\mathrm{T}$ cells provide bidirectional

(c) The Author(s). 2019 Open Access This article is distributed under the terms of the Creative Commons Attribution 4.0 International License (http://creativecommons.org/licenses/by/4.0/), which permits unrestricted use, distribution, and 
signaling that is critical for the activation, maturation, and effector function of both cell types.

CD40 expression on epithelium, leukocytes, and vascular endothelium is elevated in organ-specific autoimmune diseases such as Crohn's disease, ulcerative colitis, and rheumatoid arthritis and in systemic autoimmunity such as systemic lupus erythematosus (SLE). In addition, CD40+ monocytes, dendritic cells, and B cells are enriched at sites of chronic inflammation. Disruption of this signaling pathway has the potential to reduce production of proinflammatory cytokines, reduce $\mathrm{T}$ helper cell function, and inhibit macrophage activation, making it a very attractive therapeutic target for patients with chronic inflammatory disease [3]. X-ray structural studies have reported the CD40L-CD40 complex where 2 CD40 receptor monomers were bound to the intersubunit grooves of the CD40L trimer [4]. This protein-protein association was in part enabled by the receptor's long and flexible structural fold containing 3 tandem cysteine-rich domains (CRDs). Each CD40 monomer associated within the CD40L intersubunit groove through variety of polar and hydrophobic interactions. Charge complementarity specifically played a large role in this association. An antibody that would prevent these interactions would act as an antagonist.

Attempts to disrupt the CD40-CD40L pathway for the treatment of autoimmunity and transplant rejection have been limited due to safety issues linked to the functional properties of specific biologic therapies. Two mAb programs (BG9588, Biogen; IDEC-131, IDEC) targeting CD40L entered clinical development for Systemic Lupus Erythematosis (SLE) and Crohn's disease [3]. Development of both BG9588 and IDEC-131 was halted after multiple cases of thrombosis were reported. Subsequent studies suggested that antibodies against CD40L expressed on platelets may be cross-linked by Fc $\gamma \mathrm{R}$ also on platelets resulting in platelet degranulation and aggregation [5, 6]. Antibodies directed against CD40 such as BMS-224819 have been shown to block CD40-CD40L binding but have partial agonist activity resulting in some signaling through $\mathrm{CD} 40$ and peripheral B cell depletion [7]. In addition to B cell depletion, antibodies with CD40 agonist activity produce increases in liver enzymes and cytokine release that present safety concerns in patients with autoimmune disease [8]. Due to the various functional properties of anti-CD40 mAbs, it was critical to understand the molecular interactions of antiCD40 mAbs with CD40. Therefore, we determined the crystal structures of ABBV-323 (antagonist) Fab alone and ABBV-323 and FAB516 (agonist) Fabs complexed to the 3 extracellular domains of human CD40 along with in vitro functional assays to better understand the protein interactions that govern agonist and antagonist activity of CD40 mAbs. Here we describe the molecular interactions that produce the full antagonist activity of ABBV-323. ABBV-323 (ravagalimab) has completed phase 1 testing in healthy volunteers and is currently entering phase 2 studies for the treatment of ulcerative colitis.

\section{Results}

To identify CD40 specific antibodies, hybridoma technology was applied by immunizing mice with human CD40 antigen and adjuvant. Hybridoma antibodies were screened based on the following criteria: 1) human $\mathrm{CD} 40$ binding and neutralization of $\mathrm{CD} 40\left(\mathrm{EC}_{50}<10\right.$ $n M)$, 2) no evidence of agonist activity in reporter assays or on primary human cells (>100 nM), 3) retention of potent antagonist activity after expressing $\mathrm{VH}$ and $\mathrm{VL}$ as human chimeric antibodies, and 4) cross-reactivity to cynomolgus monkey CD40.

One chimeric antibody from the primary screen was selected for humanization, and affinity and liability engineering resulting in the lead $\mathrm{mAb}$. Several variants of the humanized lead were produced by introducing semi-rational mutations in HCDR2. An HCDR2 S56G mutation variant was chosen to move forward due to a 10 -fold improvement in affinity. Leucine to alanine mutations in the Fc region $(234 / 235)$ were introduced to minimize FcgR binding and Fc-mediated effector function. Mutations that enhanced FcRn binding (T250Q, M428 L) were introduced to increase antibody half-life. We used a CD40-dependent NF-kB reporter assay to screen for potent CD40 antagonist. This system used recombinant CD40L to stimulate HEK-293 transfected with human CD40. NF-kB activation drove SEAP production which was quantitated using spectrophotometry. This was a very sensitive assay of both antagonist activity (ability to inhibit CD40-mediated signaling) and agonist activity (ability of the anti-CD40 mAbs to stimulate cells through CD40). Our lead mAb, ABBV323, is a human IgG1/K (hCg1_z,non-a allotype) antibody with minimum $\mathrm{Fc} \gamma \mathrm{R}$ binding and Fc-mediated effector function due to the introduction of Leucine to alanine mutations in the Fc region (234/235) [9]. It also contains mutations that enhance FcRn binding (T250Q, M428 L) to increase antibody half-life [10]. ABBV-323 was a potent $\mathrm{CD} 40$ antagonist as measured in this reporter assay $\left(\mathrm{EC}_{50}=3.7 \mathrm{nM}\right)$ and showed no evidence of agonist activity in the absence of CD40L (data not shown).

We developed a primary B cell assay to test the antagonist and agonist activity of anti-CD40 mAbs in a more physiologically relevant system. B cells express the highest levels of CD40 of any cell type in human peripheral blood and also express Fc $\gamma \mathrm{R}$ which allowed us to evaluate potential for residual $\mathrm{Fc} \gamma \mathrm{R}$ binding in promoting CD40 agonist activity. To measure antagonist activity, Jurkat cells were used as a source of native CD40L and 
CD40-dependent B cell activation was measured by cell proliferation and induction of CD86 by flow cytometry. ABBV-323 inhibited CD86 upregulation on primary human $\mathrm{B}$ cells with an $\mathrm{EC}_{50}$ value of $0.6 \mathrm{nM}$ (Fig 1a). In the agonist assay a known CD40 agonist, CP-870,893 [11], dose-dependently induced CD86 expression on B cells while ABBV-323 showed no evidence of agonist activity (Fig. 1b).

Receptor crosslinking is known to be critical to initiate downstream signaling for TNF receptor family members. Although Fc crosslinking was suggested to play an important role under certain conditions, it was shown to be not essential for agonizing CD40 receptor (Richman, et al. Cancer Immunol Res. 2014) [12-14]. On the contrary, we have demonstrated that the antibody binding epitope plays an important role in function and that the Fc crosslinking is not required for agonist activity.

A crystal structure of ABBV-323 Fab was solved to $1.74 \AA$ resolution and the ABBV-323 Fab/CD40 complex structure was solved to $2.84 \AA$ resolution. Critical observations include the identification of the 3-dimensional conformational epitope of ABBV-323 and the key structural rearrangement needed for its Fab to accommodate the CD40 antigen. The structure of ABBV-323 Fab alone illustrates two loops (HCDR2 and LCDR1) which create a cleft of approximately $25 \AA$ with a diversity of charge (Fig. 2). The structure of ABBV-323 Fab bound to CD40 exhibits two complexes in the asymmetric unit. Within the asymmetric unit, each complex contains one CD40 monomer associated with the Fab on CRD2 (Fig. 3). When overlaying the two complexes within the repeating crystal unit, there is a slight shift in CRD3 due to the inherent flexibility of the cysteine rich domains, however the epitope contacts to CRD2 are constant. When comparing the complex structure with the Fab alone structure, there is a backbone shift in HCDR2 that allows opening of the cleft to accommodate CD40 binding (Fig. 3). As described earlier, mutation data supports this structural observation: a HCDR2 S56G residue change results in 20-fold improvement in binding affinity due to higher flexibility introduced by a glycine at this position. This flexibility most likely aids Fab cleft opening and facilitates a hydrogen bond interaction of $(\mathrm{H}) \mathrm{R} 55$ with $\mathrm{CD} 40$.

The conformational epitope of ABBV-323 shows several critical interactions. Specifically, CD40 residue K94 inserts into the central cleft of ABBV-323 and specifically binds to a negatively charged region outlined by residues (L)D97 and the backbone carbonyl of (H)G101 (Fig. 4a and b). Additional epitope interactions are observed for both heavy and light chains: CD40 E64 displays hydrogen bonds to $(\mathrm{H}) \mathrm{S} 53 /(\mathrm{H}) \mathrm{Y} 50$ and CD40 T99 displays a hydrogen bond to (L)N31. When overlaying the complex structure with a previously reported structure of CD40/CD40L (PDB code: 3QD6 [4]), the CD40 antigens adopt similar conformations in the region of CRD1 and CRD2. From the superposition, the Fab HCDR2 would minimally clash with several residues on an external loop of CD40L (amino acid residues S128-K143). Therefore, it is conceivable that this loop could move to accommodate simultaneous binding of CD40L, CD40 monomer and Fab in an agonist-like ternary complex.

When generating symmetry crystallographic equivalents of the CD40/ABBV-323 Fab complex, CD40 is observed as a tight antiparallel homodimer (Fig. 5a). The interface of the homodimer spans approximately $40 \AA$ long with extensive hydrogen bond complementarity and VDW contacts, and a buried surface area of 3292.5 $\AA^{2}$. Additionally, a PISA analysis predicts this homodimeric interface to be stable in solution with a calculated $\Delta \mathrm{G}_{\text {diss }}=24.3 \mathrm{kcal} / \mathrm{mol}$. Not only is ABBV-323 bound to the primary monomer ("monomer 1"), a second monomer ("monomer 2") of the crystallographic dimer associates with ABBV-323 through the $\mathrm{N}$-terminal end of CD40's CRD1 which includes the amino acid residues
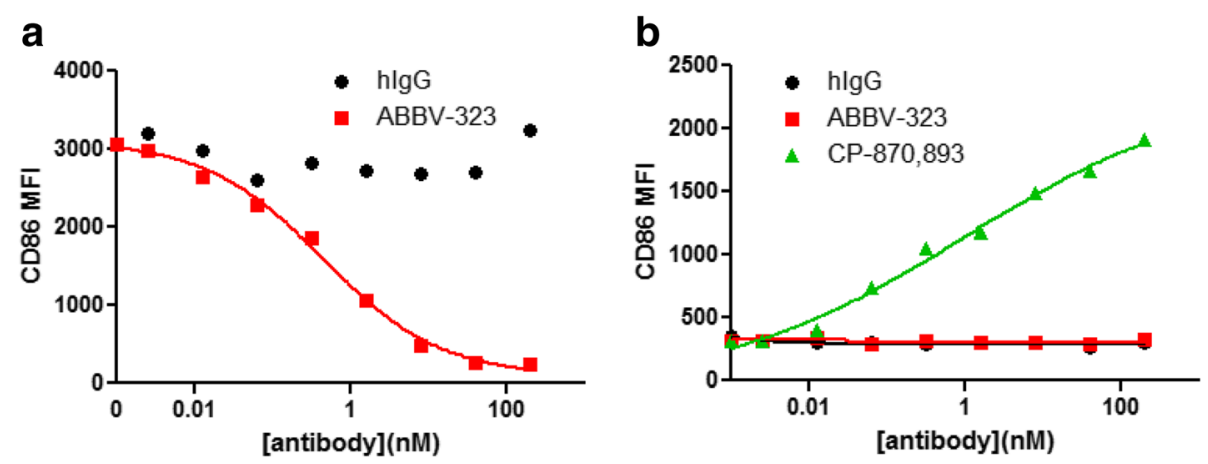

Fig. 1 a and b: (a) ABBV-323 strongly inhibits CD40 signaling in B cells (inhibition of CD86 expression) without inducing agonist activity (stimulation of CD86 expression). To measure antagonist activity, CD40L+ jurkat cells were used to stimulate primary human B cells $+/-$ ABBV-323. (b) To measure agonist activity, B cells were incubated with anti-CD40 antibodies 


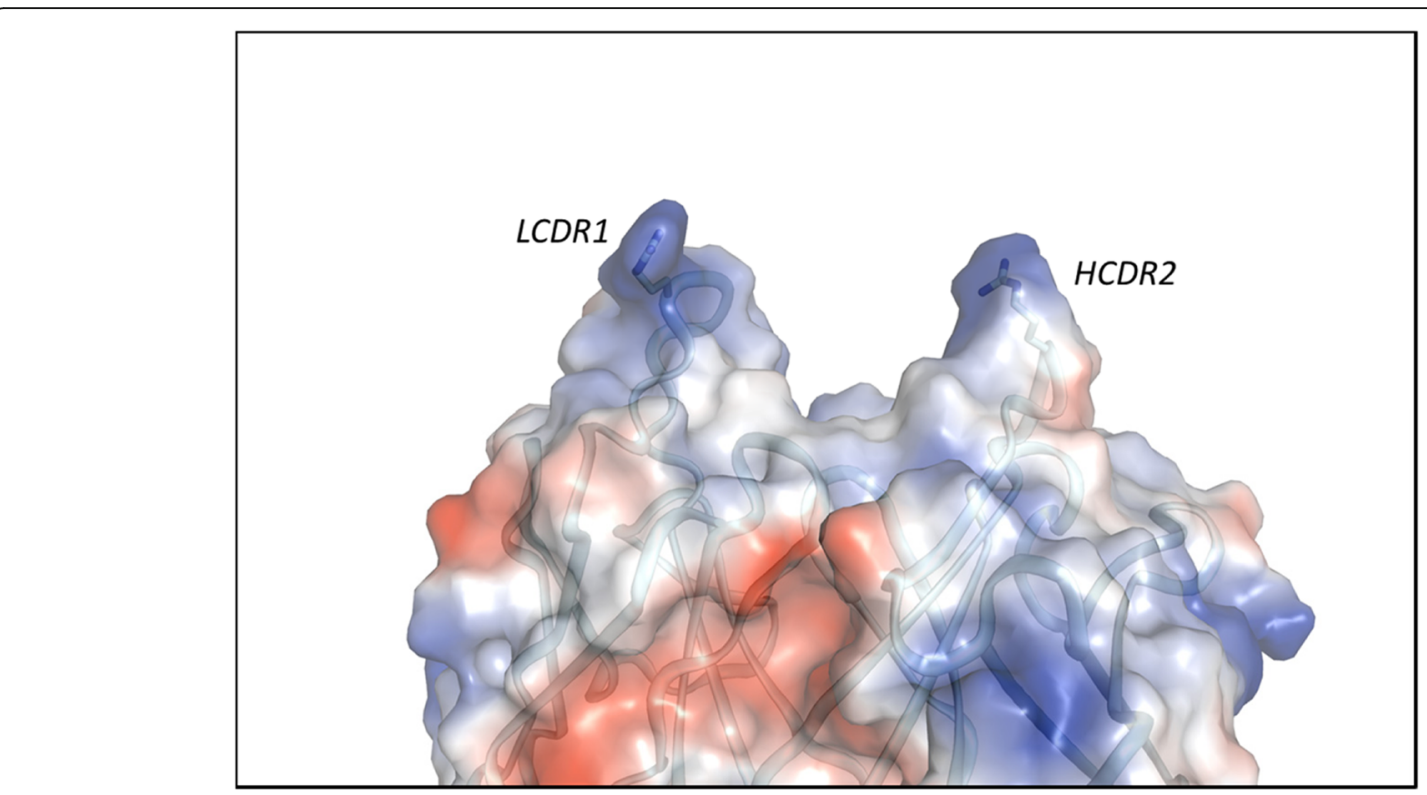

Fig. 2 Electrostatic potential surface calculated in Pymol for Fab ABBV-323 crystal structure. A cleft is formed between HCDR2 and LCDR1. Red patches refer to negative charged regions and blue patches refer to positive charged regions

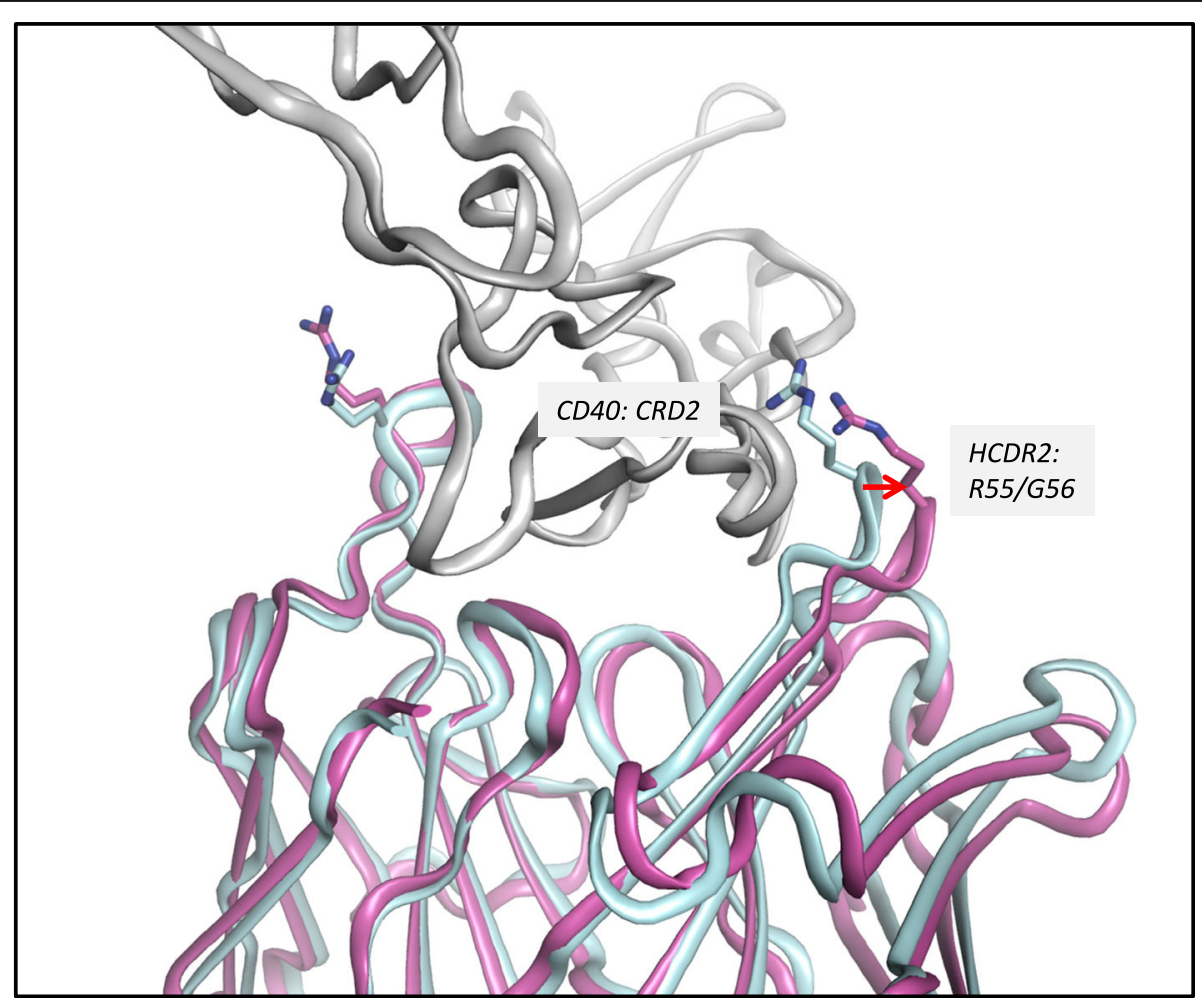

Fig. 3 Complex structure of ABBV-323 Fab (magenta) and human CD40 (shown in grey). The Fab alone structure is superimposed (in cyan) to show how HCDR2 opens to accommodate CD40 

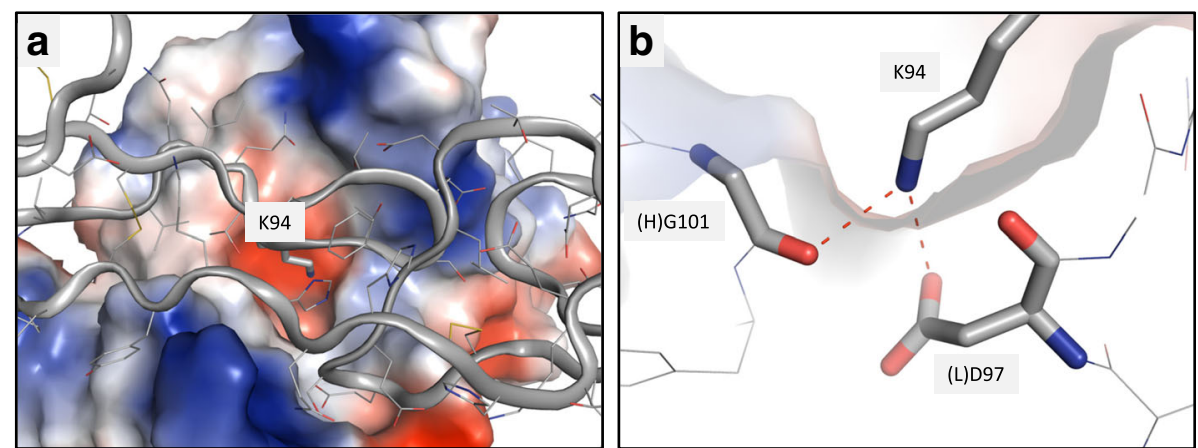

Fig. 4 a and b: (a) K94 inserts into a negatively charged channel to make interactions with acidic pocket. (b) Interactions between K94 and $(\mathrm{H}) \mathrm{G} 101 /(\mathrm{L}) \mathrm{D} 97$ are illustrated

T24-C37. Specifically, a position off of the Fab's LCDR1, (L)R32 bridges two strands of CD40 CRD1 contacting backbone carbonyls from CD40 (monomer 2) A25/S35 and a potential sidechain interaction with Q36 (Fig. 5b). This observation led to a structural hypothesis that ABBV-323 recognizes a biologically relevant CD40 "inactive" antiparallel homodimer.

The concept behind a CD40 functional dimer is also supported by a previous report where CD40 1) demonstrated homodimerization in soluble and cell surfaceexpressed environments, and 2) CD40 dimerization was dependent on the extracellular domain [15]. Additionally, a homology model was created of the homodimer based on the ligand-free TNFR1 structure and mutations in the CRD1 domain of CD40 were made based on the dimeric model. When mutating K29 (a key dimerization residue in the model) to a non-polar or acidic residue (K29A and K29E), self-assembly decreased [15]. In our reported crystal structure of ABBV-323 Fab complexed to $\mathrm{CD} 40, \mathrm{~K} 29$ participates in the observed antiparallel crystallographic dimer. Specifically, K29 is proximal to the dimeric interface and makes a potential interaction with a nearby residue from the second CD40 monomer E28. It is likely that these two residues engage in a stabilizing hydrogen bond interaction for the CD40 homodimer. Therefore, mutating this residue position to a non-polar or acidic residue could negatively affect selfassembly which requires charge complementarity for dimerization.

Structural insights from previous reports suggest that unliganded TNF family receptors dimerize in antiparallel orientations between the first two disulfide-rich motifs

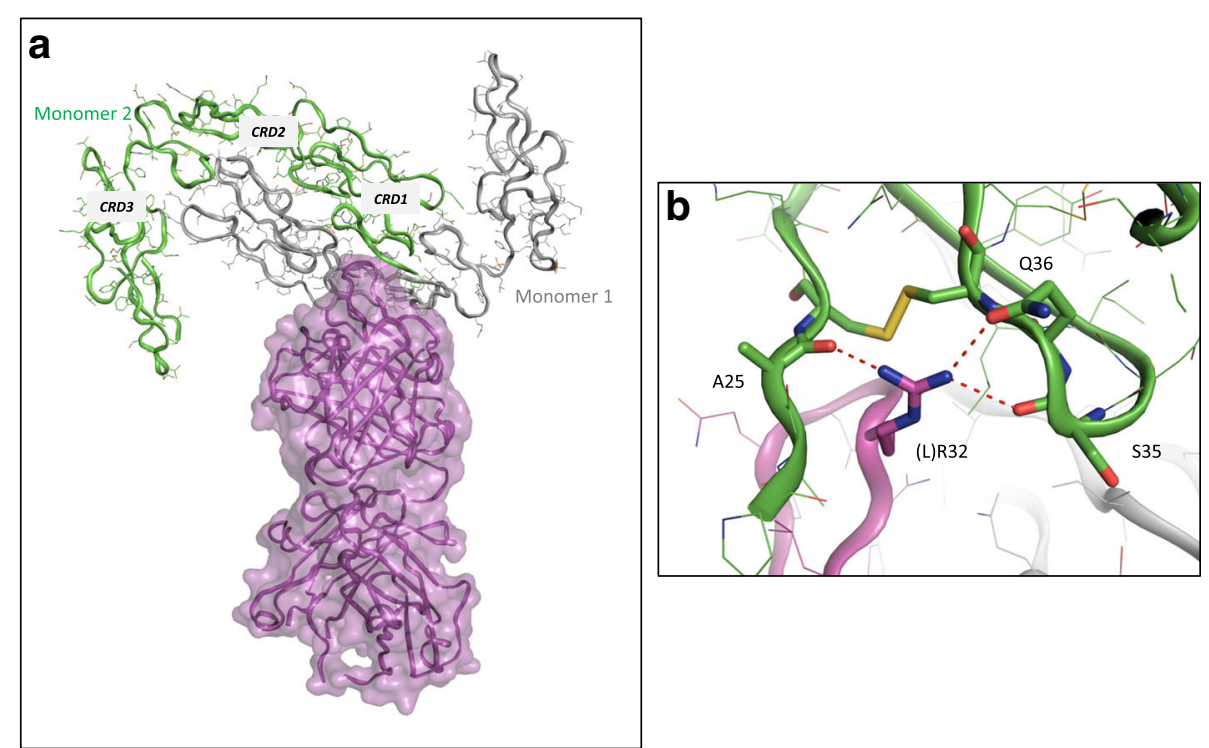

Fig. 5 a and b: (a) Two crystallographic CD40 monomers associate to form a tight antiparallel dimer (grey, green) which bind to ABBV-323 Fab (shown in magenta). (b) LCDR1 R32 inserts in the second crystallographic monomer shown in green. R32 makes interactions with backbone carbonyls to A25/S35 and sidechain Q36 
of the receptor thereby forming a non-signaling structural state $[16,17]$. This is potentially a similar scenario for CD40 receptor which is a member of the TNFa superfamily. Antiparallel CD40 homodimers would prevent downstream cytoplasmic signaling proteins to bind to $\mathrm{CD} 40$ receptor because 1) CD40 antiparallel dimers would occlude the CD40L binding site which would then 2) prevent CD40 from clustering to recruit TRAF adaptor proteins that activate different signaling pathways [13]. The co-crystal structure of ABBV-323 Fab/ CD40 supports this idea. When comparing the CD40 antiparallel dimer with a previously reported TNFR1 antiparallel dimer, the antiparallel recognition is different: CD40 dimerizes with a larger buried surface area via the CRD1-2 domains while TNFR1 dimerizes primarily through the CRD2 domain with a smaller buried dimeric surface area (1475 A2, Additional file 1: Figure S1) [16]. When overlaying the ABBV-323 Fab complex structure (including the crystallographic antiparallel homodimer) with the historical structure of CD40/CD40L (PDB code 3QD6 [4]), the superposition demonstrates that CD40L would be unable to bind the antiparallel homodimer of CD40 due to steric clashes spanning approximately 16 $\AA$, specifically in the CD40L loop region L195-I205 (Fig. 6). We therefore conclude that ABBV-323 functions as a CD40 antagonist antibody due to its ability to capture the non-signaling dimeric state of CD40 receptor which sterically masks CD40L recognition. A better understanding of the molecular basis for agonist and antagonist activity of anti-CD40 antibodies is critical for the rational design of therapeutics with the desired efficacy and tolerability profile.

To further support this idea of a non-signaling dimeric state, we examined several variants of ABBV323 with small changes to sequence in LCDR1 including changing position (L)R32 to proline (FAB516) or leucine (FAB518). These changes resulted in conversion of the antibody from antagonist to agonist activity as demonstrated in a human CD40 reporter assay (Fig. 7a, b; Table 1). This supports the claim that the LCDR1 loop in ABBV-323 (specifically amino acid position R32) may be critical in binding the second monomer of CD40 through specific polar interactions and thereby stabilizing the inactive antiparallel homodimer. When changing this residue to a non-polar leucine or proline, this functional dimer would not form due to lack of polar contacts with LCDR1. We predicted that $\mathrm{x}$-ray complexes of agonist variants such as FAB516 or FAB518 (which respectively have a proline ((L)P32) and leucine $((\mathrm{L}) \mathrm{L} 32)$ in place of an arginine on LCDR1) would exhibit different crystallization packing and oligomerization in contrast to ABBV-323. To confirm this hypothesis, the crystal structure of agonist FAB516 Fab complexed to $\mathrm{CD} 40$ was solved to $3.1 \AA$ resolution. The structure shows very clear electron density for the $\mathrm{CD} 40 / \mathrm{Fab}$ interface and crystallographic packing is unambiguous. Comparison of the two antibody complexes (CD40/ABBV-323 and CD40/FAB516) was then needed to understand oligomerization of the receptor.

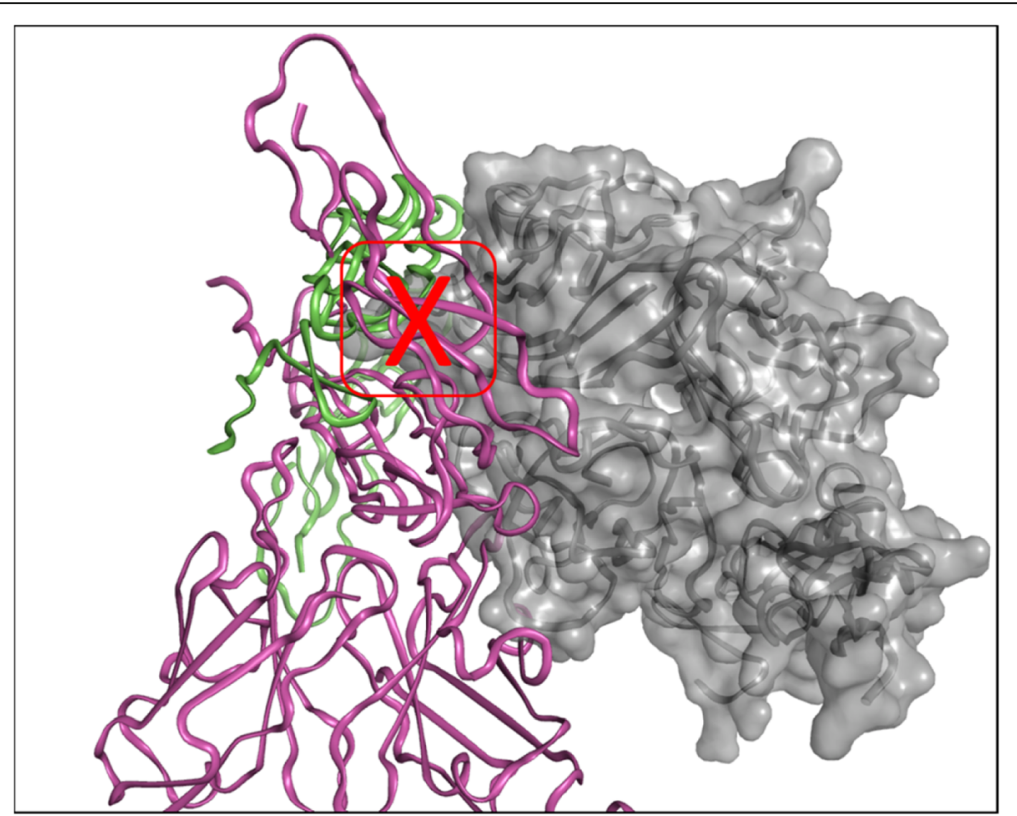

Fig. 6 Overlay of ABBV-323/CD40 complex (magenta = Fab/CD40 monomer 1, green = CD40 crystallographic monomer 2) with crystal structure of CD40L/CD40 complex (PDB code: 3QD6 in grey surface) [4]. Red outlined box shows the region of significant steric clash between CD40 dimer and CD40L 

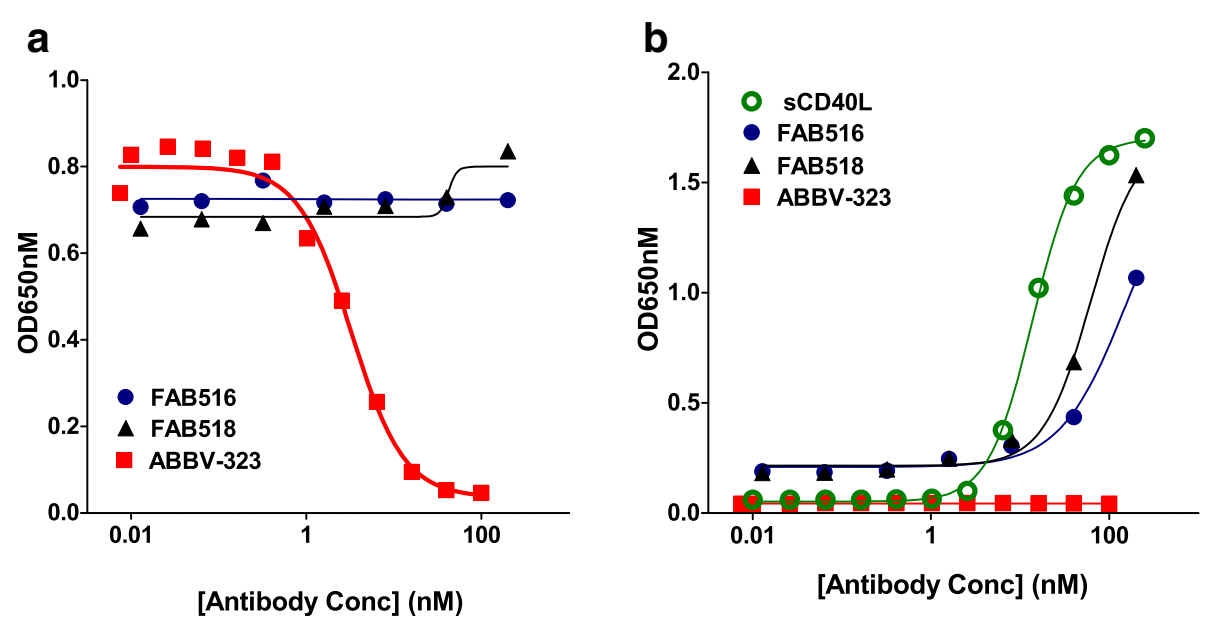

Fig. 7 a and b: (a) ABBV-323 was incubated with HEK-293 CD40L cells in the presence of CD40L expressing D1.1 cells. The ability of ABBV-323 to inhibit the interaction between CD40 and its receptor CD40L is monitored by the production of SEAP compared to an lgG control. (b) Agonist activity is monitored as above with the following exception: CD40L-expressing D1.1 cells were replaced with assay media. CD40L was titrated alongside ABBV-323 as a positive control (Concentration range $=250 \mathrm{ng} / \mathrm{ml}-0.026 \mathrm{ng} / \mathrm{ml}$ )

\section{Discussion}

When overlaying the backbones of FAB516 and ABBV323 CD40 complex structures, the CD40 monomer recognition for both Fabs is identical. However as predicted, the crystallographic dimer formation is different. When generating the symmetry equivalents of the FAB516 complex structure, an antiparallel CD40 dimer is again observed however the second CD40 monomer is in a different orientation when compared to the CD40 homodimer in the ABBV-323 complex structure (Fig. 8a and b). A PISA analysis for the FAB516-CD40 complex calculates the crystallographic CD40 homodimer interface to have a smaller buried surface area (1397.6 $\AA 2)$ and a smaller predicted $\Delta \mathrm{G}_{\text {diss }}(2.5 \mathrm{kcal} /$ $\mathrm{mol}$ ) when compared to the values calculated for the ABBV-323 complex suggesting that the FAB516 CD40 dimer interface is less physiologically relevant. Most importantly, the FAB516 Fab binds predominantly to one monomer of CD40. Specifically, LCDR1 (L)L32 does not engage in interactions with a second CD40 monomer (Fig. 8b) for 4 out of the 5 Fab-antigen complexes in the asymmetric unit. Due to these observations, we conclude that FAB516 recognizes CD40 monomer and not the functional homodimer as illustrated with the ABBV-323 complex.
This difference in CD40 recognition supports the agonist activity seen for FAB516. When observing a superposition of the backbone structure of the FAB516 complex structure with the CD40L/CD40 complex structure (PDB code 3QD6 [4]), there are several clashes between the FAB516/CD40 monomeric complex and CD40L, specifically in the region of the heavy chain CDRs. This observation is in agreement with blocking results (Table 1). However, with some structural rearrangement, an agonist ternary complex (CD40/ CD40L/FAB516, Fig. 9a and b) could also be hypothesized suggesting that FAB516 could act potentially as an agonist stabilizer. Specifically, when minimizing the proposed ternary complex, HCDR2 (residues S52-G56) and CD40L (residues S128-K132) conformationally adjust to create the complex. This concept is in agreement with reporter assay results in Table 1 (Fig. $7 \mathrm{a}$ and $\mathrm{b}$ ).

We conclude that a non-polar residue at position LCDR1(32) as seen in FAB518 (proline) and FAB516 (leucine), allows agonist antibody recognition of monomeric CD40 and a potential ternary complex with CD40L. In contrast, when this position switches to a basic polar residue (specifically in the case of antagonist ABBV-323 (L)R32), the antibody recognizes an antiparallel dimeric CD40 which prevents CD40L binding.

Table 1 Measuring agonist and antagonist activities of several CD40 antibody variants

\begin{tabular}{lllll}
\hline Antibody variants & $\begin{array}{l}\text { VL LCDR1 Sequence } \\
\text { (KSSQSLLNSGNQKNYLT) }\end{array}$ & Blocking of CD40L & $\begin{array}{l}\text { Agonist: huCD40 } \\
\text { reporter assay IC50 nM }\end{array}$ & $\begin{array}{l}\text { Antagonist: Jurkat/ } \\
\text { Reporter assay IC50 nM }\end{array}$ \\
\hline ABBV-323 & KSSQSLLNRGNQKNYLT & Yes & No & 3.1 \\
FAB518 & KSSQSLLNPGNQKNYLT & Yes & 62 & No \\
FAB516 & KSSQSLLNLGNQKNYLT & Yes & 157 & No \\
\hline
\end{tabular}



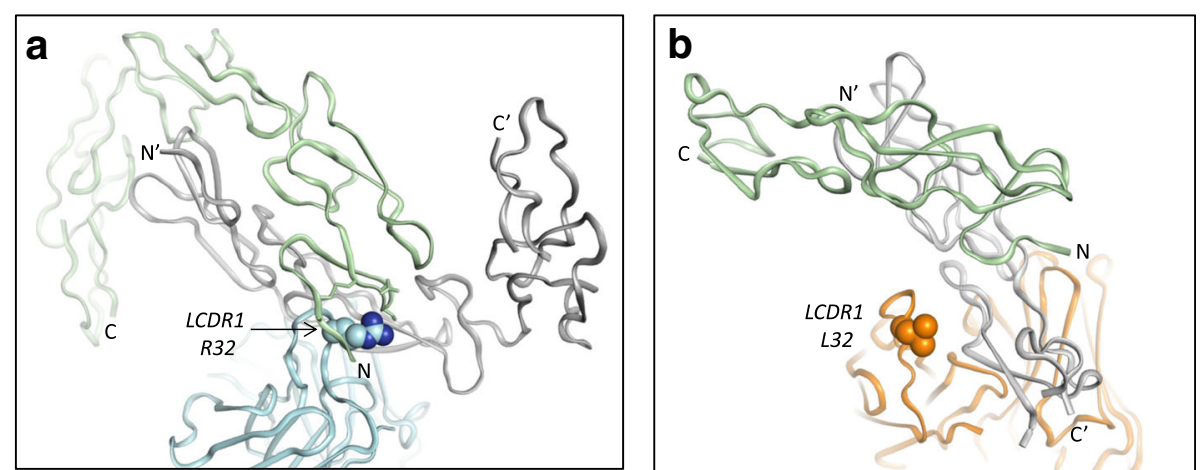

Fig.8 a and b (a) ABBV-323 Fab (blue) bound to crystallographic CD40 dimer (second monomer shown in green ribbon) which shows interaction with LCDR1 R32. (b) FAB516 Fab (orange) bound to crystallographic CD40 dimer (second monomer shown in green ribbon) which shows no interaction with LCDR1 L32. N and C termini are also labeled to demonstrate the antiparallel dimers for both ABBV-323 and FAB516

\section{Conclusion}

In this study, the structures of ABBV-323 Fab alone and ABBV-323/FAB516 Fabs in complex to CD40 were solved. The structure of ABBV-323 demonstrates a unique method for antagonism by stabilizing the proposed functional antiparallel dimer for CD40 receptor via novel contacts to LCDR1, namely R32. This was further supported by a closely related agonist antibody FAB516 which showed only monomeric recognition and no contacts with LCDR1 due to a mutation to L32 on LCDR1. Therefore, a structural agonist/antagonist switch in this class of antibodies was identified. Antibodies for antiparallel dimers have also been recently reported for the TNFR2 receptor in the inhibition of proliferation of ovarian cancer cells [18]. In this report, a model was created demonstrating how the TNFR2 antiparallel dimer locked into its quiescent state via the antagonist antibody to prevent TNF binding and signaling. It was also hypothesized that these resting state TNFR2 dimers could also arrange into a higher order hexagonal lattice on the cell surface. Although we did not observe a hexagonal arrangement in the crystal packing of the ABBV-323/CD40 complex structure, it would be interesting to observe the nature of the CD40 resting state antiparallel dimers using orthogonal techniques such as SAXS or Cryo-EM with the potential of observing higher order CD40 oligomerization. In conclusion, our structural findings which demonstrate the ABBV-323 antibody's mechanism of action suggest a growing strategy for designing and identifying antagonists to not only CD40 receptor but other members of the TNF superfamily.

\section{Methods}

\section{Bioactivity measurement of CD40 antibodies - primary B} cell assay

Primary human B cells were purchased from BioSpecialty and were used to study CD40 signaling. Cells were cultured in RPMI with $10 \%$ heat-inactivated serum, $2 \mathrm{mM} \mathrm{L-}$ glutamine, $1 \mathrm{mM}$ sodium pyruvate and $100 \mu \mathrm{g} / \mathrm{ml}$ Pen Strep. To measure agonist activity, the cells were plated at 0.1 million per well of a 96-well plate and dilutions of CD40 antibodies were incubated with the cells for 2 days. Cells were then harvested and CD86 upregulation was
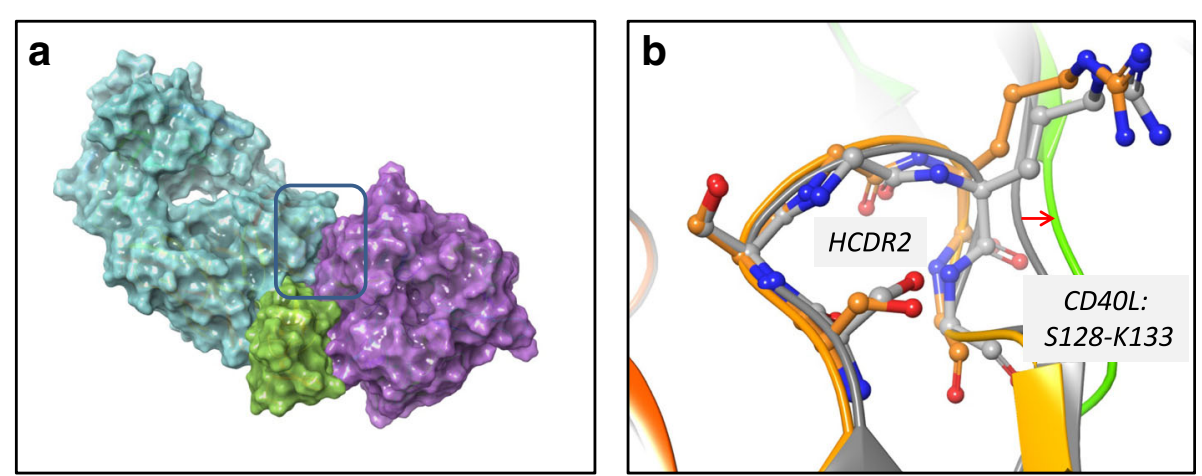

Fig. 9 a and b: (a) Model of potential ternary complex of agonist FAB516 Fab (cyan), human CD40 (green), human CD40L (purple). Box outlines region where minor structural rearrangements may occur to accommodate agonist complex. (b) After ternary complex minimization in MAESTRO, HCDR2 (S52-G56) and CD40L (S128-K132) residues shift to accommodate the interface between CD40L, FAB516 and CD40 
measured by FACS. To assess antagonist activity, B cells were incubated with CD40L-expressing Jurkat cells (ATCC CRL-10915) at 2:1 ratio per well of 96-well plate in the presence of CD40 antibodies. Cells were harvested 2 days later and stained for CD19, CD20 (B cell marker) and CD86. Briefly, cells were washed by PBS and incubated with antibodies in PBS with $2 \%$ serum for $20 \mathrm{~min}$ on ice. The cells were then washed by PBS and analyzed by a BD LSRFortessa ${ }^{\mathrm{Tw}}$ cell analyzer. Anti-CD19 and antiCD20 were purchased from BD bioscience and anti-CD86 was from eBiosciences. The ability of the anti-CD40 antibodies to inhibit the interaction between CD40 and its receptor CD40L was compared to an IgG control.

\section{HEK-293 blue CD40L - antagonist reporter assay}

HEK-293 Blue CD40L Cells were seeded into 96-well flat bottom TC plates at a density of $5 \times 10^{4}$ cells $/ 100 \mu \mathrm{l} /$ well. The plates were incubated for $1 \mathrm{~h}$ at $37^{\circ} \mathrm{C}, 5 \%$ $\mathrm{CO} 2$. Stock solutions of CD40 antibodies were prepared in assay medium at a $4 \mathrm{x}$ concentration $(400 \mathrm{nM})$, serially diluted 1:2.5 and added to HEK-293 cells (50 $\mu \mathrm{l} /$ well). CD40L-expressing D1.1 cells were diluted to a concentration of $1 \times 10^{6} / \mathrm{ml}$ in assay media and added to all wells $(50 \mu \mathrm{l} /$ well) bringing the final Ratio of D1.1 to HEK-293 to 1:1. Plates were incubated for $18 \mathrm{~h}$ at $37^{\circ} \mathrm{C}$, $5 \% \mathrm{CO} 2$. Following incubation, $50 \mu \mathrm{L}$ of supernatant media was removed and transferred to a new plate for QUANTI-Blue luminescence detection. IC50 values were obtained using logarithm of antibody concentration vs. luminescence nonlinear regression (4-parameter dose-response curve model:

$$
\begin{aligned}
\mathrm{Y}= & \text { Bottom } \left.+(\text { Top-Bottom }) /\left(1+10^{\wedge}\left((\text { LogIC50-X })^{*} \text { HillSlope }\right)\right)\right) \\
& \text { in GraphPad Prism } 5 . \text { Three independent experiments } \\
& \text { were performed. }
\end{aligned}
$$

\section{HEK-293 blue CD40L - agonist reporter assay}

Assay performed as above with the following exception: CD40L-expressing D1.1 cells were replaced with $50 \mu \mathrm{l}$ assay media. A 4x stock solution of recombinant human MegaCD40L (positive control) was prepared at $1 \mu \mathrm{g} / \mathrm{ml}$ in assay media and serially diluted $1: 2.5$. Dilutions were added alongside CD40 antibodies. Concentration range $=250 \mathrm{ng} / \mathrm{ml}-0.026 \mathrm{ng} / \mathrm{ml}$.

\section{Preparation and purification of CD40 antigen}

A DNA sequence encoding the human CD40 extracellular domain (UNIPROT P25942; amino acids 1193) was synthesized and cloned into our proprietary pHybE (US Patent 8187836 B2) vector followed by an in-frame C-terminal $\mathrm{Tev}$ protease cleavage site and hexahistidine tag (sequence ENLYFQGHHHHHH).
The pHybE expression vector utilizes an EF-1 $\alpha$ promoter and an OriP origin of replication derived from Epstein-Barr virus (EBV). This plasmid was transfected into HEK-293-6E cells (NRC Canada) grown in Freestyle 293 medium (Thermo Fischer) at $1 \times 10^{6}$ cells $/ \mathrm{ml}$ using the transfection reagent Polyethylenimine (PEI, Polysciences Inc) at a PEI:DNA ratio of 4: 1 . The transfected cell culture was fed with tryptone$\mathrm{N} 1$ (Organotechnie) (to $0.5 \%$ ) at $24 \mathrm{~h}$ post-transfection. On day 7 post-transfection, the transfected cell culture was cleared by centrifugation followed by filtration through $0.2 \mu \mathrm{m}$ PES filter (Corning). Cleared medium was buffer exchanged to PBS, pH 7.4 using a Kvick TFF system equipped with $10 \mathrm{kDa}$ membranes (GE Healthcare) and loaded on a $5 \mathrm{ml}$ HisTrap FF column (GE Healthcare) equilibrated with PBS, pH 7.4. The column was washed with $25 \mathrm{mM}$ imidazole in PBS, pH 7.4 and bound protein was eluted with $250 \mathrm{mM}$ imidazole in PBS, $\mathrm{pH}$ 7.4. Eluted protein was concentrated using Amicon Ultra-15 centrifugal filter devices (Millipore) with $10 \mathrm{kDa}$ molecular weight cutoff, and further purified by SEC on a 26/60 Superdex 200 column (GE Healthcare) equilibrated and run with PBS, pH 7.4. Fractions containing CD40 were pooled, concentration measured by absorbance at 280 $\mathrm{nm}$, and samples analyzed by SEC, SDS-PAGE, and mass spectrometry. [CD40(h)(21-193)]-Tev-His6 was stored in aliquots at $-80^{\circ} \mathrm{C}$.

\section{Preparation and purification of CD40 ABBV-323 Fab fragment}

Fab fragment of CD40 ABBV-323 was prepared by papain cleavage of the parent mAb ABBV-323 as detailed below. Papain (Worthington Biochemical, Lakewood, NJ) was activated with $50 \mathrm{mM}$ cysteine in PBS, pH 7.4 buffer. The parent mAb in PBS, pH 7.4 buffer was mixed with papain at 1:100 weight ratio of papain to $\mathrm{mAb}$ and incubated for $1 \mathrm{~h}$ at $37^{\circ} \mathrm{C}$. The reaction was quenched with $5 \mathrm{mM}$ iodoacetamide. The mixture was purified on $10 \mathrm{ml}$ Mab SelectSure resin (GE Healthcare) where the Fab fragment was collected as flow through. The flow through was concentrated using an Ultrafree-15 Biomax $10 \mathrm{kDa}$ molecular weight cut-off (MWCO) centrifugal device (Millipore). The concentrated mixture was purified on $2.6 \mathrm{~cm} \times 60 \mathrm{~cm}$ Sephacryl 200 HiPrep column (GE Healthcare) pre-equilibrated in $50 \mathrm{mM}$ HEPES, $50 \mathrm{mM}$ $\mathrm{NaCl}$, pH 7.5 buffer. Fractions containing Fab fragment (monitored by UV absorbance at $280 \mathrm{~nm}$ ) were pooled and frozen at $-80^{\circ} \mathrm{C}$. Sample purity was assessed by analytical SEC, SDS-PAGE and mass spectrometry. Table 3 lists protein quality characterizations for the reagents used in this study. 


\section{CD40/CD40 ABBV-323 Fab complex preparation}

Recombinant human CD40 was expressed and purified as described above. Recombinant human CD40 and CD40 ABBV-323 Fab protein were mixed at a $1.05: 1 \mathrm{M}$ ratio $(1.8 \mathrm{mg} / \mathrm{ml}$ final concentration) and incubated for $4 \mathrm{~h}$ at $4{ }^{\circ} \mathrm{C}$. The complex sample was loaded onto a $2.6 \mathrm{~cm} \times 60$ cm Sephacryl 200 HiPrep column (GE Healthcare) preequilibrated in $50 \mathrm{mM}$ HEPES, $50 \mathrm{mM} \mathrm{NaCl}$, pH 7.5 buffer at $1 \mathrm{ml} / \mathrm{min}$. Fractions containing the complex (monitored by UV absorbance at $280 \mathrm{~nm}$ ) were pooled and concentrated to $18 \mathrm{mg} / \mathrm{ml}$ using an Ultrafree-15 Biomax $10 \mathrm{kDa}$ molecular weight cut-off (MWCO) centrifugal device (Millipore). Sample purity was assessed by analytical SEC and SDS-PAGE. Excess Fab-Complex protein was stored frozen at $-80^{\circ} \mathrm{C}$.

\section{ABBV-323 Fab crystallization}

Fab alone was supplied at $22.5 \mathrm{mg} / \mathrm{ml}$ in $50 \mathrm{mM}$ HEPES, $50 \mathrm{mM} \mathrm{NaCl}, \mathrm{pH} 7.5$. Crystals grew by vapor diffusion at $23^{\circ} \mathrm{C}$. The reservoir contained 25\% (w/v) PMME 550, $0.1 \mathrm{M}$ MES $\mathrm{pH} 6.5,0.01 \mathrm{M}$ zinc sulfate. The drop was made by adding equal volumes of protein and reservoir solution. Crystals grew as thick prisms and were cryoprotected using the reservoir solution with the addition of $10 \%(\mathrm{v} / \mathrm{v})$ propylene glycol. Crystals were harvested, swished through cryo-solution and cryo-cooled directly in liquid nitrogen. Diffraction data to $1.74 \AA$ were collected under gaseous nitrogen at $100 \mathrm{~K}$ at the 17ID beamline at the Advanced Photon Source at Argonne National Laboratories (Argonne IL).

\section{ABBV-323 Fab complexed to CD40 antigen crystallization}

The Fab complex was supplied at $18 \mathrm{mg} / \mathrm{ml}$ in $50 \mathrm{mM}$ HEPES, $50 \mathrm{mM} \mathrm{NaCl}, \mathrm{pH} 7.5$. The antigen construct used was [CD40 (h) (21-193)]-TEV-6His. Crystals grew by vapor diffusion at $23^{\circ} \mathrm{C}$. The reservoir contained $2 \mathrm{M}$ ammonium sulfate, $0.1 \mathrm{M}$ phosphate-citrate $\mathrm{pH} 4.2$. The drop was made by adding equal volumes of protein and reservoir solution. Crystals grew as thin rods and were cryo-protected using $2.5 \mathrm{M}$ lithium sulfate. Crystals were harvested, swished through cryo-solution and cryocooled directly in liquid nitrogen. Diffraction data to $2.84 \AA$ were collected under gaseous nitrogen at $100 \mathrm{~K}$ at the 17ID beamline at the Advanced Photon Source at Argonne National Laboratories (Argonne IL).

\section{Preparation of FAB516 complex by direct co-expression Fermentation}

The expression plasmid (pHybE) for heavy chain of FAB516 was synthesized with secretion leader sequence, variable region, $\mathrm{CH} 1$ and hinge region (ending at $\mathrm{H} 224$, $\mathrm{Eu}$ numbering). The light chain plasmid ( $\mathrm{pHybE}$ ) was synthesized with secretion leader sequence, variable region and $\mathrm{CL}$ region (ending at $\mathrm{C} 214, \mathrm{Eu}$ numbering).
The plasmid for antigen expression was constructed as described above. HEK-293-6E cells, which is a suspension adapted human embryonic kidney-293-based cell line stably expressing the Epstein-Barr virus nuclear antigen (EBNA1), were transfected with plasmid DNA encoding the heavy chain (HC) and light chain (LC) of FAB516 and plasmid for the CD40 antigen ([CD40(h)(1193)]-TEV-6His). For a $3 \mathrm{~L}$ expression, a $5 \mathrm{~L}$ flask (Thompson Instrument Company) containing cells at $1.2 \times 10^{6}$ cells/flask were grown in Freestyle 293 Expression medium at a temperature of $37^{\circ} \mathrm{C}$, with $8 \% \mathrm{CO} 2$, and shaking at $80 \mathrm{rpm}$. For transfection, $1.5 \mathrm{mg}$ of DNA in 1:2:3 ratio (HC:LC:Antigen) was mixed with $6 \mathrm{ml}$ of 1 $\mathrm{mg} / \mathrm{ml} \mathrm{pH} \mathrm{7.0} \mathrm{PEI} \mathrm{solution} \mathrm{in} \mathrm{a} \mathrm{volume} \mathrm{of} 150 \mathrm{ml}$ Freestyle medium. After $10 \mathrm{~min}$ of incubation, the mixture was added to the cells. Tryptone N1 (Organotechnie) in Freestyle medium was added to the flask at $24 \mathrm{~h}$ post transfection for $0.5 \%$ final concentration. The conditioned medium was harvested 9-11 days post transfection by centrifugation at $16 \mathrm{~K}$ x G for $10 \mathrm{~min}$, followed by clarification through a Pall AcroPak $500 \quad 0.8 / 0.45 \mu \mathrm{m}$ filter capsule, and sodium azide was added from a $1 \mathrm{M}$ stock to a concentration of $5 \mathrm{mM}$. The conditioned media was stored at $4{ }^{\circ} \mathrm{C}$ until purified.

\section{CD40/CD40 FAB516 Fab complex preparation}

The cell culture supernatant containing Fab/antigen complex was loaded onto a $22 \mathrm{ml} \mathrm{Ni}$ Excel (GE Life Sciences) column at a flow rate of $5 \mathrm{ml} / \mathrm{min}$, and washed with 5 column volumes of binding buffer $(50 \mathrm{mM}$ Tris, $350 \mathrm{mM}$ sodium chloride, $\mathrm{pH}$ 8.0). The non-specific proteins bound to the column were washed with 5 column volumes of binding buffer containing $20 \mathrm{mM}$ imidazole. The Fab/antigen complex was eluted by gradient elution from 5 to $100 \%$ elution buffer ( $50 \mathrm{mM}$ Tris, $300 \mathrm{mM}$ sodium chloride $400 \mathrm{mM}$ imidazole $\mathrm{pH} 8$ ) in 10 column volumes. The Fab/antigen complex was collected in $7 \mathrm{ml}$ fractions. Size-exclusion chromatography was performed as a polishing step using a HiLoad 26/60 Superdex 75 column (GE Life Sciences). The Superdex 75 column was run at $1 \mathrm{ml} / \mathrm{min}$ with $50 \mathrm{mM}$ HEPES, $50 \mathrm{mM} \mathrm{NaCl}$ pH 7.5. Fractions containing Fab/antigen complex was characterized with SEC, SDS-PAGE gel and mass spec, and concentrated to $20.0 \mathrm{mg} / \mathrm{ml}$ for crystallography.

\section{FAB516 Fab complexed to CD40 antigen crystallization}

The Fab complex crystals grew by vapor diffusion using sitting drop at $23{ }^{\circ} \mathrm{C}$. The reservoir contained $1.6 \mathrm{M}$ Ammonium Sulfate, 2\% w/v PEG1000, 100 mM HEPES Sodium Salt pH 7.5 (JBS-II screen from Jena Bioscience, conditions A9). The drop was made by adding equal volumes of protein and reservoir solution $(0.4 \mu \mathrm{L}+0.4 \mu \mathrm{L})$. Diffracting crystals took 11 months to appear and were cryo-protected using the reservoir solution with $20 \%$ 
Table 2 Crystallographic statistics

\begin{tabular}{|c|c|c|c|}
\hline Structure & $\begin{array}{l}\text { ABBV-323 } \\
\text { Fab alone }\end{array}$ & $\begin{array}{l}\text { CD40 complexed } \\
\text { to ABBV-323 }\end{array}$ & $\begin{array}{l}\text { CD40 complexed } \\
\text { to FAB516 }\end{array}$ \\
\hline PDB code & 6PE7 & 6PE8 & 6PE9 \\
\hline \multicolumn{4}{|l|}{ Data Collection } \\
\hline Resolution $(\AA)$ & $132.6-1.74$ & $126.9-2.84$ & $167.5-3.13$ \\
\hline Space Group & $\mathrm{C} 222_{1}$ & $P 2,2,2$ & C2 \\
\hline Unit Cell Lengths ( $a, b, c ; \AA)$ Angles $\left(^{\circ}\right.$ ) & $\begin{array}{l}63.7 \\
130.4 \\
132.6\end{array}$ & $\begin{array}{l}173.3 \\
76.0 \\
126.1\end{array}$ & $\begin{array}{l}254.8 \\
224.0 \\
111.4 \\
\beta=98.0\end{array}$ \\
\hline Unique reflections & 56956 & 40335 & 108254 \\
\hline \multicolumn{4}{|l|}{ Overall Statistics (Highest Shell) } \\
\hline $\mathrm{R}_{\text {merge }}(\%)$ & $0.041(0.94)$ & $0.11(0.974)$ & $0.108(0.632)$ \\
\hline $1 / \sigma_{l}$ & $25.5(2.2)$ & $15.8(2.3)$ & $11.2(2.1)$ \\
\hline Data completeness (\%) & $100(100)$ & $100(100)$ & $99.4(98.6)$ \\
\hline Mean multiplicity & $6.6(6.6)$ & $6.6(6.8)$ & $3.4(3.2)$ \\
\hline$C C(1 / 2)$ & $1.00(0.79)$ & $1.00(0.72)$ & $0.99(0.76)$ \\
\hline \multicolumn{4}{|l|}{ Refinement } \\
\hline Resolution $(\AA)$ & $24.4-1.74$ & $38.0-2.84$ & $35.3-3.13$ \\
\hline Reflections used in refinement & 56860 & 40063 & 107879 \\
\hline $\mathrm{R}_{\text {cryst }}(\%)$ & 19.6 & 20.5 & 21.6 \\
\hline$R_{\text {free }}(\%)$ & 23.0 & 26.5 & 25.5 \\
\hline R.m.s. deviations, bond lengths $(\AA)$, bond angles $\left(^{\circ}\right)$ & $0.005,0.865$ & $0.010,1.13$ & $0.010,1.13$ \\
\hline Ramachandran Favored regions (\%) & 97.7 & 94.9 & 93.6 \\
\hline Outliers (\%) & 0.23 & 0.17 & 0.21 \\
\hline
\end{tabular}

Ethylene glycol. Crystals were harvested, swished through cryo-solution and cryo-cooled directly in liquid nitrogen. Diffraction data to $3.13 \AA$ were collected under gaseous nitrogen at $100 \mathrm{~K}$ at the 17ID beamline at the Advanced Photon Source at Argonne National Laboratories (Argonne IL).

\section{Structure determinations of ABBV-323 Fab and CD40 antigen complexes}

Diffraction data for both crystal structures were processed using the program AUTOPROC with isotropic scaling from Global Phasing Ltd. [19] The ABBV-323 Fab dataset was processed in the space group C222 1 with the following unit cell dimensions: $a=64.65 \mathrm{~b}=130.4$ $\mathrm{c}=132.6$. A maximum likelihood molecular replacement solution was determined using the program PHASER [20] using a Fab search model reported previously (Protein Data Bank entry 3QOS [21]). Coordinates for 1 Fab molecule in the asymmetric unit were generated based on the molecular replacement solution. Preliminary refinement of the resulting solution was conducted using REFMAC [22, 23] and the program BUSTER [24]. Iterative protein model building was conducted using the program COOT [25] and examination of 2Fo-Fc and Fo-Fc electron-density maps. Water molecules were added using BUSTER refinement [24]. A final round of

Table 3 Protein quality characterization

\begin{tabular}{|c|c|c|c|c|c|}
\hline \multirow{2}{*}{$\begin{array}{l}\text { Protein } \\
\text { name }\end{array}$} & \multicolumn{2}{|l|}{ Isotype } & \multirow{2}{*}{$\begin{array}{l}\text { Monomer } \\
\% \text { by SEC }\end{array}$} & \multirow{2}{*}{$\begin{array}{l}\text { Endotoxin } \\
\text { level }^{\mathrm{a}}\end{array}$} & \multirow{2}{*}{$\begin{array}{l}\text { Mass } \\
\text { Spec. } \\
\text { Identity }^{\text {b }}\end{array}$} \\
\hline & Heavy chain & Light chain & & & \\
\hline FAB518 & hCg1_z,non-a & Kappa & 100 & $<0.1 \mathrm{EU} / \mathrm{mg}$ & Consistent \\
\hline FAB516 & hCg1_z,non-a & Kappa & 100 & $<0.1 \mathrm{EU} / \mathrm{mg}$ & Consistent \\
\hline CP 870,893 & hCg1_z,non-a & Kappa & 99 & $<0.1 \mathrm{EU} / \mathrm{mg}$ & Consistent \\
\hline ABBV-323 & hCg1_z,non-a & Kappa & 100 & $<0.4 \mathrm{EU} / \mathrm{mg}$ & Consistent \\
\hline
\end{tabular}

${ }^{a}$ Endotoxin levels assessed by PTS EndoSafe LAL

${ }^{\mathrm{b}}$ Expected (theoretical) molecular weight (MW) is consistent with measured MW by Mass Spec 
refinement was conducted using PHENIX [26]. Final refinement statistics reported $R_{\text {free }} / R_{\text {work }}$ values of $0.230 / 0.196$.

The ABBV-323 Fab CD40 complex dataset was processed in the space group $\mathrm{P} 2{ }_{1} 2_{1} 2$ with the following unit cell dimensions: $\mathrm{a}=173.3 \mathrm{~b}=76.0 \mathrm{c}=126.1$. A maximum likelihood molecular replacement solution was determined using the program PHASER [20] using the previously solved ABBV-323 Fab reported above. Coordinates for $2 \mathrm{Fab}$ molecules were found in the asymmetric unit based on the molecular replacement solution. Preliminary refinement of the resulting solution was conducted using REFMAC $[22,23]$ and the program BUSTER [24]. The model for CD40 was built manually using the program COOT [25] and examination of 2Fo-Fc and Fo-Fc electron-density maps. Water molecules were added using BUSTER refinement [24]. A final round of refinement was conducted using PHENIX [26]. Final refinement statistics reported $R_{\text {free }} / R_{\text {work }}$ values of $0.265 / 0.205$.

The FAB516 Fab CD40 complex dataset was processed in the space group $\mathrm{C} 2$ with the following unit cell dimensions: $\mathrm{a}=254.8 \mathrm{~b}=224.0 \mathrm{c}=111.4 \beta=98.0$. A maximum likelihood molecular replacement solution was determined using the program PHASER [20] using the previously solved ABBV-323 complex structure reported above. Coordinates for $5 \mathrm{Fab} / \mathrm{CD} 40$ complexes were found in the asymmetric unit based on the molecular replacement solution. Preliminary refinement of the resulting solution was conducted using REFMAC $[22,23]$ and the program BUSTER [24]. A partial model for CD40 was built manually using the program COOT [25] and examination of 2Fo-Fc and Fo-Fc electron-density maps. CRD3 was not seen in electron density for all 5 CD40 monomers. Additionally, one Fab molecule (monomers $\mathrm{K}$ and $\mathrm{M}$ ) only had the variable regions fit due to disordered density in the constant region. A final round of refinement was conducted using PHENIX [26].The refinement statistics reported $R_{\text {free }} / R_{\text {work }}$ values of $0.255 / 0.216$.

Ramachandran plots and statistics were calculated using MolProbity in the Validation tools from PHENIX [26]. Plots and outliers are included in Additional file 2: Figures: S2a-c.

The ternary complex model of FAB516/CD40L/CD40 presented in Fig. 9a and b was created using the crystal structures of FAB516/CD40 and 3QD6 [4] as guides. The complex was minimized in the program MAESTRO [27] with Prime loop refinement [28] for HCDR2 S52-G56.

\section{Additional files}

Additional file 1: Figures S1a, b and c: (a) Overlay of TNFR antiparallel dimer as observed in PDB 1NCF (in blue) and CD40-ABBV-323 antiparallel dimer (in green). (b) and (c) show the antiparallel orientations with $\mathrm{N}$ and $\mathrm{C}$ termini labeled. (PPTX $328 \mathrm{~kb}$ )

Additional file 2: Figure S2a, b and c: Ramachadran plots and outliers for all three structures were generated in the program PHENIX (Molprobity) [26]. (PPTX 558 kb)

\section{Abbreviations}

CD40: Cluster of differentiation 40; CD40L: CD40 ligand; CDR: Complementarity-determining region; CRD: Cysteine-rich domain; FAB: Fragment antigen binding domain; HCDR: Heavy chain CDR; ICAM1: Intercellular adhesion molecule 1; LCDR: Light chain CDR; mAb: Monoclonal antibody; NF-KB: Nuclear factor kappa light chain enhancer; SEAP: Secreted embryonic alkaline phosphatase; Tev: Tobacco Etch Virus nuclear-inclusion-1 endopeptidase; TNF: Tumor necrosis factor; TRAF: TNF receptor associated factor

\section{Acknowledgements}

Use of the IMCA-CAT beamline 17-ID (or 17-BM) at the Advanced Photon Source was supported by the companies of the Industrial Macromolecular Crystallography Association through a contract with Hauptman-Woodward Medical Research Institute.

Use of the Advanced Photon Source was supported by the U.S. Department of Energy, Office of Science, Office of Basic Energy Sciences, under Contract No. DE-AC02-06CH11357.

We would like to acknowledge former AbbVie employee, Junjian Liu, for helpful discussions at the start of this research.

\section{Authors' contributions}

MAA solved and analyzed all $x$-ray structures, formed structural hypoth eses and was primary author on the paper. $L B, I D, D A E, L G, A G, J H 1, R B I$, RAJ, ML, DCP, RS, BS, SS, and RW performed and interpreted laboratory experiments and delivered reagents or data for the study. MAA, ID, RAJ, $J H 2$, and BLM discussed strategy and results of the study. MAA, ID, RJ, $\mathrm{JH} 2, \mathrm{RBI}, \mathrm{BS}$, and BLM helped write the manuscript. All authors are em ployees of AbbVie and have read and approved the manuscript. The de sign, study conduct, and financial support for this research were pro vided by AbbVie. AbbVie participated in the interpretation of data, re view, and approval of the publication.

\section{Funding}

Not applicable.

\section{Availability of data and materials}

Table 2 lists data collection and refinement statistics from all structures listed above. All structural figures were created in the program Pymol

(Schrödinger) [29]. All structural coordinates have been deposited to the Protein Data Bank (http://www.rcsb.org) with the following PDB codes: 6PE7, 6PE8, 6PE9. Table 3 lists protein quality characterizations for the reagents used in this study.

\section{Ethics approval and consent to participate}

Not applicable.

\section{Consent for publication}

Not applicable.

\section{Competing interests}

The authors declare that they have no competing interests.

\section{Author details}

${ }^{1}$ AbbVie Bioresearch Center, 381 Plantation Street, Worcester, MA 01605, USA. ${ }^{2}$ AbbVie Bioresearch Center, 100 Research Drive, Worcester, MA 01605, USA.

${ }^{3}$ AbbVie Inc., 1 North Waukegan Road, North Chicago, IL 60064, USA.

Received: 17 April 2019 Accepted: 17 July 2019

Published online: 05 August 2019

References

1. Bishop GA, Moore CR, Xie P, Stunz LL, Kraus ZJ. TRAF proteins in CD40 signaling. Adv Exp Med Biol. 2007;597:131-51. 
2. Hostager BS, Haxhinasto SA, Rowland SL, Bishop GA. Tumor necrosis factor receptor-associated factor 2 (TRAF2)-deficient B lymphocytes reveal novel roles for TRAF2 in CD40 signaling. J Biol Chem. 2007;278:45382-90.

3. Law CL, Grewal IS. Therapeutic interventions targeting CD40L (CD154) and CD40: the opportunities and challenges. Adv Exp Med Biol. 2009;647:8-36.

4. An HJ, Kim YJ, Song DH, Park BS, Kim HM, Lee JD, Paik SG, Lee JO, Lee H. Crystallographic and mutational analysis of the CD40-CD154 complex and its implications for receptor activation. J Biol Chem. 2011;286:11226-35.

5. Koyama I, Kawai T, Andrews D, Boskovic S, Nadazdin O, Wee SL, Sogawa H, Wu DL, Smith RN, Colvin RB, Sachs DH, Cosimi AB. Thrombophilia associated with anti-CD154 monoclonal antibody treatment and its prophylaxis in nonhuman primates. Transplantation. 2004;77:460-2.

6. Robles-Carrillo L, Meyer T, Hatfield M, Desai H, Dávila M, Langer F, Amaya M, Garber E, Francis JL, Hsu YM, Amirkhosravi A. Anti-CD40L immune complexes potently activate platelets in vitro and cause thrombosis in FCGR2A transgenic mice. J Immunol. 2010;185:1577-83.

7. Adams AB, Shirasugi N, Jones TR, Durham MM, Strobert EA, Cowan S, Rees P, Hendrix R, Price K, Kenyon NS, Hagerty D, Townsend R, Hollenbaugh D, Pearson TC, Larsen CP. Development of a chimeric anti-CD40 monoclonal antibody that synergizes with LEA29Y to prolong islet allograft survival. J. Immunol. 2005:174:542-50

8. Hunter TB, Alsarraj M, Gladue RP, Bedian V, Antonia SJ. An agonist antibody specific for CD40 induces dendritic cell maturation and promotes autologous anti-tumour T-cell responses in an in vitro mixed autologous tumour cell/lymph node cell model. Scand J Immunol. 2007;65:479-86.

9. Wines BD, Powell MS, Parren PW, Barnes N, Hogarth PM. The lgG fc contains distinct fc receptor ( $F C R$ ) binding site: the leukocyte receptors fc gamma Rl and fc gamma Rlla bind to a region in the fc distinct from that recognized by neonatal FCR and protein a. J Immunol. 2000;164:5313-8.

10. Hinton PR, Xiong JM, Johlfs MG, Tang MT, Keller S, Tsurushita N. An engineered human IgG1 antibody with longer serum half-life. J Immunol. 2006;176:346-56.

11. Gladue RP, Paradis T, Cole SH, Donovan C, Nelson R, Alpert R, Gardner J, Natoli E, Elliot E, Shepard R, Bedian V. The CD40 agonist antibody CP-870,893 enhances dendritic cell and B-cell activity and promotes anti-tumor efficacy in SCID-hu mice. Cancer Immunol Immunother. 2011:60:1009-17.

12. Li F, Ravetch JV. Inhibitory Fcy receptor engage,ent drives adjuvant and anti -tumor activities of agonistic CD40 antibodies. Science. 2011;333:1030-40.

13. White AL, Chan HTC, Roghanian A, French RR, Mockridge Cl, Tutt AL, Dixon SV, Ajona D, Verbeek JS, Al-Shamkhani A, Cragg MS, Beers SA, Glennie MJ. Interaction with FCYRIIB is critical for the agonist activity of anti-CD40 monoclonal antibody. J Immunol. 2011;187:1754-63.

14. Richman LP, Vonderheide RH. Role of crosslinking for agonistic CD40 monoclonal antibodies as immune therapy of cancer. Cancer Immunol Res. 2014;2:19-26.

15. Smulski CR, Beyrath J, Decossas M, Chekkat N, Wolff $P$, Estieu-Gionnet K, Guichard G, Speiser D, Schneider P, Fournel S. Cysteine-rich domain 1 of CD40 mediates receptor self-assembly. J Biol Chem. 2013;288: 10914-22.

16. Naismith JH, Devine TQ, Brandhuber BJ, Sprang SR. Crystallographic evidence for dimerization of unliganded tumor necrosis factor receptor. J Biol Chem. 1995;270:13303-7.

17. Vanamee ES, Faustman DL. Structural principles of tumor necrosis factor superfamily signaling. Sci Signal. 2018;11:1-11.

18. Torrey H, Butterworth J, Mera T, Okubo Y, Wang L, Baum D, Defusco A, Plager S, Warden S, Huang D, Vanamee E, Foster R, Faustman DL. Targeting TNFR2 with antagonist antibodies inhibits proliferation of ovarian cancer cells and tumor-associated $T_{\text {regs. }}$ Sci Signal. 2017;10:1-12.

19. Vonrhein C, Flensburg C, Keller P, Sharff A, Smart O, Paciorek W, Womack T, Bricogne G. Data processing and analysis with the autoPROC toolbox. Acta Cryst D Biol Crystallogr. 2011;67:293-302.

20. McCoy AJ, Grosse-Kunstleve RW, Adam PD, Winn MD, Storoni LC, Read RJ. Phaser crystallographic software. J Appl Crystallogr. 2007:40:658-74.

21. Malia TJ, Obmolova G, Almagro JC, Gilliland GL, Teplyakov A. Crystal structure of human germline antibody 3-23/B3. Mol Immunol. 2011; 48:1586-8.

22. Winn MD, Ballard CC, Cowtan KD, Dodson EJ, Emsley P, Evans PR, Keegan RM, Krissinel EB, Leslie AGW, McCoy A, McNicholas SJ, Murshudov GN, Pannu NS, Potterton EA, Powell HR, Read RJ, Vagin A, Wilson KS. Overview of the CCP4 suite and current developments. Acta Cryst. D Biol. Crystallogr. 2011;67:235-42.
23. Murshodov GN, Vagin AA, Dodson EJ. Refinement of macromolecular structures by the maximum-likelihood method. Acta Cryst D Biol Crystallogr. 1997;53:240-55.

24. Bricogne $G$, Blanc E, Brandl M, Flensburg C, Keller P, Paciorek W, Roversi $P$, Sharff A, Smart OS, Vonrhein C, Womack TO. BUSTER version 2.9.7. Cambridge, United Kingdom: Global phasing Itd; 2011.

25. Emsley P, Cowtan K. Coot: model-building tools for molecular graphics. Acta Cryst D Biol Crystallogr. 2004;60:2126-32.

26. Adams PD, Afonine PV, Bunkoczi G, Chem VB, Davis IW, Echols N, Headd JJ, Hung LW, Kapral GJ, Grosse-Kunstleve RW, McCoy AJ, Moriarty NW, Oeffner R, Read RJ, Richardson DC, Richardson JS, Terwilliger TC, Zwart PH. PHENIX: a comprehensive python-based system for macromolecular structure solution. Acta Cryst D Biol Crystalllogr. 2010;66:213-21.

27. Schrödinger Release 2018-3. Maestro, Schrödinger. New York, NY: LLC; 2019

28. Jacobson MP, Pincus DL, Rapp CS, Day TJF, Honig B, Shaw DE, Friesner RA. A hierarchical approach to all-atom protein loop prediction. Proteins. 2004;55:351-67.

29. The PyMOL Molecular Graphics System, Version 1.4 Schrödinger, LLC.

\section{Publisher's Note}

Springer Nature remains neutral with regard to jurisdictional claims in published maps and institutional affiliations.

\section{Ready to submit your research? Choose BMC and benefit from:}

- fast, convenient online submission

- thorough peer review by experienced researchers in your field

- rapid publication on acceptance

- support for research data, including large and complex data types

- gold Open Access which fosters wider collaboration and increased citations

- maximum visibility for your research: over $100 \mathrm{M}$ website views per year

At BMC, research is always in progress.

Learn more biomedcentral.com/submissions 